\title{
Risks versus benefits of medication use during pregnancy: what do women perceive?
}

This article was published in the following Dove Press journal:

Patient Preference and Adherence

\author{
Bianca Mulder,' Maarten \\ J Bijlsma,' Catharina CM \\ Schuiling-Veninga,' Leonard \\ P Morssink, ${ }^{2}$ Eugene van \\ Puijenbroek, ${ }^{3,4}$ Jan G \\ Aarnoudse, ${ }^{5}$ Eelko Hak, \\ Tjalling W de Vries ${ }^{6}$ \\ 'Groningen Research Institute of \\ Pharmacy, Unit PharmacoTherapy, \\ Epidemiology \& Economics, \\ University of Groningen, Groningen, \\ the Netherlands; ${ }^{2}$ Department \\ of Obstetrics and Gynaecology, \\ Medical Center Leeuwarden, \\ Leeuwarden, the Netherlands; \\ ${ }^{3}$ Netherlands Pharmacovigilance \\ Centre Lareb, 's-Hertogenbosch, \\ the Netherlands; ${ }^{4}$ Unit of \\ Pharmacotherapy and Pharmaceutical \\ Care, Department of Pharmacy, \\ University of Groningen, Groningen, \\ the Netherlands; ${ }^{5}$ Department \\ of Obstetrics and Gynaecology, \\ University Medical Center \\ Groningen, University of Groningen, \\ Groningen, the Netherlands; \\ ${ }^{6}$ Department of Pediatrics, Medical \\ Center Leeuwarden, Leeuwarden, \\ the Netherlands
}

Background: Understanding perception of risks and benefits is essential for informed patient choices regarding medical care. The primary aim of this study was to evaluate the perception of risks and benefits of 9 drug classes during pregnancy and associations with women's characteristics.

Methods: Questionnaires were distributed to pregnant women who attended a Dutch Obstetric Care facility (first- and second-line care). Mean perceived risk and benefit scores were computed for 9 different drug classes (paracetamol, antacids, antibiotics, antifungal medication, drugs against nausea and vomiting, histamine-2 receptor antagonists/proton pump inhibitors, antidepressants, nonsteroidal anti-inflammatory drugs, and sedatives/anxiolytics). For each participant, we computed weighted risk and benefit sum scores with principal component analysis. In addition, major concerns regarding medication use were evaluated.

Results: The questionnaire was completed by 136 women (response rate $77 \%$ ). Pregnant women were most concerned about having a child with a birth defect (35\%), a miscarriage (35\%), or their child developing an allergic disease $(23 \%)$, respectively, as a result of drug use. The majority of studied drug classes were perceived relatively low in risk and high in benefit. Higher risk scores were reported if women were in their first trimesters of pregnancy $(p=0.007)$. Lower benefit scores were reported if women were single $(p=0.014)$, smoking $(p=0.028)$, nulliparous ( $p=0.006)$, or did not have a family history of birth defects $(p=0.005)$.

Conclusion: Pregnant women's concerns regarding potential drug adverse effects were not only focused on congenital birth defects but also included a wider range of adverse outcomes. This study showed that most of the studied drug classes were perceived relatively low in risk and high in benefit.

Keywords: drugs, perception, risks, benefits, worries, pregnancy

\section{Background}

The majority of pregnant women use medication during pregnancy. ${ }^{1}$ Despite increasing availability of information about teratogenic risks, medication use during pregnancy still causes uncertainty and concern among pregnant women and their health care providers. ${ }^{2,3}$

Recent risk perception studies observed that women tend to overestimate the magnitude of teratogenic risks. ${ }^{2-15}$ Although it is difficult to estimate the real risk of medication use during pregnancy, unrealistic perception of risk among pregnant women may lead to poor adherence, discontinuation of treatment, and even abortion of otherwise wanted and healthy infants. ${ }^{9,14}$ Counseling enables a more balanced decision on the use of medication during pregnancy. ${ }^{8,11,13}$ However, the manner in which information is presented can make a substantial difference to people's responses. For example, providing pregnant women with positively framed information will lower risk
Correspondence: Bianca Mulder Department of PharmacoEpidemiology and PharmacoEconomics, University Centre of Pharmacy, University of Groningen, PO Box XB45, A Deusinglaan I, 97। 3 AV Groningen, the Netherlands Tel +3I 50 36I 7576

Email biancamulder@outlook.com
Patient Preference and Adherence 2018:12 I-8

(c) (7) (5) 2018 Mulder et al. This work is published and licensed by Dove Medical Press Limited. The full terms of this license are available at https://www.dovepress.com/terms.php cc) and incorporate the Creative Commons Attribution - Non Commercial (unported, v3.0) License (http://creativecommons.org/licenses/by-nc/3.0/). By accessing the work you hereby accept the Terms. Non-commercial uses of the work are permitted without any further permission from Dove Medical Press Limited, provided the work is properly attributed. For permission for commercial use of this work, please see paragraphs 4.2 and 5 of our Terms (https://www.dovepress.com/terms.php). 
perceptions significantly. ${ }^{8}$ In addition, women's perception of the benefits of medication use may have a major influence on the acceptance of risks.

In previous risk perception studies, risk was often presented as the probability of having a child with a congenital malformation. ${ }^{4,12}$ Although congenital malformations are severe adverse effects, medication use during pregnancy has been associated with a broader spectrum of disorders than congenital malformations alone. ${ }^{16-18}$ The study of Petersen et al ${ }^{15}$ presented the risk of medication use as a harmful effect for the fetus. It is likely that many women may have interpreted harmful effects broadly and considered factors such as congenital anomalies, still birth, preterm birth, low birth weight, growth retardation of the fetus, and developmental delays in totality. However, it remains unknown what the major concerns are among pregnant women regarding medication use.

The primary aim of this study is to evaluate the perception of risks and benefits of medication use during pregnancy and associations with women's sociodemographic characteristics. In addition, we evaluated the major concerns among pregnant women regarding medication use.

\section{Methods}

\section{Study design, setting, and study population}

This study was based on data from a survey of pregnant women who attended an obstetric care facility (Medical Center Leeuwarden) in the Netherlands (both first- and second-line care). Yearly about 1,900 pregnant women (1.1\% of all Dutch women) are cared for in this large ( 800 beds) teaching hospital in the northern part of the Netherlands. Researchers asked all pregnant women who were visiting the obstetric care facility for a consultation between May 1, 2013 and June 30, 2013 to participate in the study. Questionnaires were distributed by the researchers to all women willing to participate, regardless of their health status or antenatal care needs. Inclusion criteria for participation in the study were that women had to be pregnant and had to understand the Dutch language. Women who could not understand Dutch were excluded.

\section{Self-reported questionnaire}

In this study, an anonymous self-reported questionnaire was developed and used. The questionnaire consisted of 4 parts to collect data on 1) general characteristics, 2) medication use during pregnancy and information sources used, 3) major concerns related to medication use, and 4) perceived risks and benefits of medication use during pregnancy. In Dutch health care, first-line care is easily accessible and patients can contact first-line care providers without a referral. Second-line care is specialist care in hospitals where pregnant women need a referral from a general practitioner (GP) or a midwife.

A group of 10 pregnant women were asked to pretest a tested version of the questionnaire. They were interviewed to confirm if the questionnaire was clear to them and if they had comments or suggestions to state in the text box given at the end of the questionnaire. No specific comments were returned, so we concluded that the test version was good and no further changes were required. Since waiting times were often extensive, questionnaires could easily be completed by the participants.

\section{Part I - general characteristics}

Sociodemographic variables included in the questionnaire were age, education, marital status, duration of the pregnancy, gravidity, parity, status of employment, and attending first or second-line care facility. Lifestyle variables that were examined were the use of alcohol and smoking during pregnancy.

\section{Part 2 - medication use during pregnancy and information sources used}

Respondents were asked whether and which medication they used with and without a prescription during pregnancy. Classes of drugs were presented, including examples of generic and trade names. Presented drug classes were paracetamol, nonsteroidal anti-inflammatory drugs (NSAIDs), vitamins other than folic acid and vitamin $\mathrm{D}$, drugs against a cold, acid-suppressive medication, antibiotics, antifungal medication, drugs against nausea and vomiting (NVP), sedatives/anxiolytics, anti-asthma medication, anti-diabetes medication, medication against high blood pressure, and homeopathic medication. ${ }^{19}$

Folic acid and vitamin $\mathrm{D}$ are vitamins which are advised in the Netherlands during pregnancy. ${ }^{20}$ Therefore, women who only used these vitamins were categorized as nonmedication users. When prenatal vitamins were reported, we considered them as multivitamins designed for pregnant women containing more and/or other vitamins than folic acid and vitamin D.

Women were asked if they obtained information about medication before and during pregnancy. Commonly used sources of information were listed: Internet, gynecologist, GP, pharmacist, midwife, package information leaflets (PIL), friends and family, books, or others. 


\section{Part 3 - measurements of concerns}

Women were asked to rate their level of concern about having a miscarriage, preterm birth, complicated delivery, child with a birth defect, or a child with a low gestational age as a result of medication use during pregnancy. In addition, women were asked to rate their level of concern about having a child with memory/learning problems, behavioral problems, or an allergic disease. These events are not evident at birth, but are associated with medication use during pregnancy in the literature. ${ }^{16-18,21}$ Women could rate their level of concern with a score from 1 to 5 on a 5 -point scale (Table 1). ${ }^{21}$

\section{Part 4 - perceived risks and benefits of medication use during pregnancy}

Different studies on risk perception proposed that risk is dependent on the expectancy of the probability of an event and the beliefs about the potential harm. ${ }^{12,22-27}$ In this study, women were asked to rate the probability and severity of an event occurring due to exposure to several drug classes (paracetamol, antacids, antibiotics, antifungal medication, drugs against NVP, histamine-2 receptor antagonists/ proton pump inhibitors, antidepressants, NSAIDs, sedatives/ anxiolytics) on a 7-point Likert scale (Table 1). ${ }^{27}$ For each drug class, examples of generic (domperidone, metoclopramide, ibuprofen, diclofenac, naproxen, nitrofurantoin, amoxicillin, cimetidine, pantoprazole, omeprazole, citalopram, paroxetine, amitriptyline, temazepam, oxazepam, diazepam, miconazole and clotrimazole) or trade names (Motilium, Primperan, Rennie, Gaviscon, Furabid, Cipramil, Seroxat, Canesten) were given. Risk scores were obtained by

Table I Questions and scales on which concerns related to medication use, probability, severity, and benefits were rated

\begin{tabular}{|c|c|c|}
\hline Items & Questions & Scale \\
\hline Concerns & $\begin{array}{l}\text { To what extent are you } \\
\text { concerned that there is an } \\
\text { increased probability that this } \\
\text { event occurs as a result of } \\
\text { medication use? }\end{array}$ & $\begin{array}{l}\text { I= never concerned, } \\
2=\text { sometimes } \\
\text { concerned, } 3=\text { neutral, } \\
4=\text { often concerned, and } \\
5=\text { always concerned }\end{array}$ \\
\hline Probability & $\begin{array}{l}\text { How likely do you think an } \\
\text { accident or unfortunate event } \\
\text { involving this drug occurs? }\end{array}$ & $\begin{array}{l}\text { I= very unlikely; } \\
\text { 7= very likely }\end{array}$ \\
\hline Severity & $\begin{array}{l}\text { If an accident or unfortunate } \\
\text { event involving this drug } \\
\text { occurred, to what extent are } \\
\text { the harmful effects for the } \\
\text { baby and/or mother? }\end{array}$ & $\begin{array}{l}\text { I= very mild harm; } \\
\text { 7= very serious harm }\end{array}$ \\
\hline Benefits & $\begin{array}{l}\text { How beneficial do you } \\
\text { consider this drug or item to } \\
\text { be for pregnant women and } \\
\text { their babies? }\end{array}$ & $\begin{array}{l}\text { I= not at all beneficial; } \\
\text { 7= very beneficial }\end{array}$ \\
\hline
\end{tabular}

multiplication of the measures of perceived probability and severity. A square root extraction was performed to make the risk scores comparable with the benefit scores. ${ }^{23}$

To get information on the perceived benefits of medication during pregnancy, women were asked to rate the benefits of the drug classes on a scale from 1 to 7 (Table 1).

\section{Statistical analysis}

Percentages were computed for the respondents who were concerned or very concerned (scored 4 or 5 on the concern scale) about having a miscarriage, preterm birth, complicated delivery, child with a birth defect, or a child with a low gestational age as a result of medication use during pregnancy. Means and standard deviations (SDs) were computed for the perceived risk (probability times severity score) and benefit scores of the different drug classes. We also calculated Pearson's correlation coefficients between risk and benefit scores for each separate drug class.

Separate principal component analyses (PCA) were performed on the 9 different drugs on the risk scale and benefit scale, respectively. PCA was used to construct weighted risk and benefit sum scores using the loadings of the first principal component as weights. ${ }^{28,29}$ With this construction, the weighted sum scores represent unbiased estimates of standardized values on a latent variable (eg, "overall perceived benefit"). The loadings are used as weights because the size of each loading indicates the degree to which a variable represents an aspect of the underlying latent variable. Given the relatively high proportion of variance explained by each first principal component, we take their respective latent variables to represent "overall" risk and benefit, respectively. The first principal component on the risk scale explained $58.5 \%$ of the variance, whereas the first principal component of the benefit scale explained $53.4 \%$ of the variance. Barlett's test of sphericity and the Kaiser-Meyer-Olkin (KMO) test were performed to test if the number of significant correlations was sufficient to perform PCA. ${ }^{28}$ Bartlett's test of sphericity was significant $(p<0.001)$ for the 3 scales. KMO statistic showed that a factor analysis was appropriate for the risk and benefit scales ( 0.833 and 0.859 , respectively). ${ }^{29}$

Linear regression models were used to examine associations between maternal age, education level, and the weighted risk and benefit sum score. Student's $t$-test was performed to assess differences in the weighted risk and benefit sum score for the different general characteristics, medication use, and acquirement of information. All analyses were performed using the SPSS software for Windows (version 21; IBM Corporation, Armonk, NY, USA). 


\section{Ethical approval}

The institutional review board of the Medical Center Leeuwarden stated that ethical approval and patient informed consent were not required, since the study involved a questionnaire only, was completely anonymous, and no patient data were used. However, the study was approved by the institutional review board of the Medical Center Leeuwarden.

\section{Results}

\section{Response and general characteristics}

During the 2 months when the questionnaire was distributed, 177 women were informed about the study. The questionnaire was returned by 136 women (77\%). Data on general characteristics of the study population are provided in Table 2 . The mean age of the respondents was 30.8 ( $\mathrm{SD} \pm 5$ ) years. Most of the respondents (55\%) participated in the study while they were in their third trimester of pregnancy. Most of the respondents had been pregnant before (72\%) and $30 \%$ of the respondents had had a previous miscarriage.

\section{Medication use}

Most of the women (82.2\%) had used medication during pregnancy (Table 3). Paracetamol was used most commonly during pregnancy (42\%). Other commonly used drugs were vitamins $(21 \%)$, acid-suppressive medication (25\%), and

Table 2 General characteristics of study population $(\mathrm{N}=\mid 36)$

\begin{tabular}{ll}
\hline Characteristics & Number (\%) \\
\hline Mean age \pm SD (years) & $30.8 \pm 5.0$ \\
Marital status: married/cohabiting & $126(92.6)$ \\
Duration of pregnancy* & \\
$\quad$ First trimester & $16(13.8)$ \\
Second trimester & $36(31.0)$ \\
Third trimester & $64(55.2)$ \\
Nulliparity & $39(28.7)$ \\
Previous miscarriages & $4 I(30.1)$ \\
Presence of birth defects in first-degree family & $26(19.1)$ \\
Education & \\
Low level of education & $21(15.4)$ \\
Medium level of education & $53(39.0)$ \\
High level of education & $62(45.6)$ \\
Working status & \\
Not working in health care sector & $78(57.4)$ \\
Working in health care sector & $31(22.8)$ \\
Not working & $27(19.9)$ \\
Attended & \\
First-line care facility & $24(17.6)$ \\
Second-line care facility & $111(81.6)$ \\
Smoking during pregnancy & $15(I 1.0)$ \\
Alcohol consumption during pregnancy & $0(0.0)$ \\
\hline Note: $*$ Information on trimester of pregnancy is missing for 2 respondents.
\end{tabular}

Note: *Information on trimester of pregnancy is missing for 2 respondents.
Table 3 Reported medication use during pregnancy $(\mathrm{N}=136)$

\begin{tabular}{|c|c|c|c|}
\hline Type of medication & $\begin{array}{l}\text { Total } \\
\text { (\%)* }\end{array}$ & $\begin{array}{l}\text { On prescription } \\
\text { (\%) }\end{array}$ & $\begin{array}{l}\text { OTC } \\
\text { (\%) }\end{array}$ \\
\hline Total & $97(82.2)$ & $66(48.5)$ & $69(58.5)$ \\
\hline Paracetamol & $49(4 I .5)$ & II (8.I) & $4 \mathrm{I}(34.7)$ \\
\hline $\begin{array}{l}\text { Vitamins other than folic } \\
\text { acid and vitamin } D\end{array}$ & $25(21.2)$ & 0 & $25(21.2)$ \\
\hline Acid-suppressive medication & $30(25.4)$ & $10(7.4)$ & $21(17.8)$ \\
\hline Antacids & $24(20.3)$ & $4(2.9)$ & $21(17.8)$ \\
\hline $\mathrm{H} 2$-antagonists/PPIs & $6(4.4)$ & $6(4.4)$ & 0 \\
\hline Antibiotics & II (8.I) & $11(8.1)$ & 0 \\
\hline NSAIDs & I $(0.7)$ & $\mathrm{I}(0.7)$ & $0(0.0)$ \\
\hline Antifungal medication & $7(5.1)$ & $7(5.1)$ & $\mathrm{I}(0.8)$ \\
\hline Antidepressants & $5(4.2)$ & $5(4.2)$ & 0 \\
\hline Cardiovascular medication & $8(5.9)$ & $8(5.9)$ & 0 \\
\hline Anti-diabetes medication & $4(2.9)$ & $4(2.9)$ & 0 \\
\hline Anti-allergy medication** & $6(4.4)$ & $6(4.4)$ & 0 \\
\hline Laxatives & $6(4.4)$ & $6(4.4)$ & 0 \\
\hline Iron supplementation & $10(8.5)$ & $10(8.5)$ & 0 \\
\hline Thyrax & $9(7.6)$ & $9(7.6)$ & 0 \\
\hline Anti-cold medication & $10(8.5)$ & 0 & $10(8.5)$ \\
\hline Other & $22(16.2)$ & I5 (II.0) & $10(7.4)$ \\
\hline
\end{tabular}

Notes: *Women could have used both on prescription and OTC medication; hence, the number for total medication use is lower than the sum of on prescription and OTC medication use. **This group contains medication for the treatment of eczema, asthma, or hay fever.

Abbreviations: OTC, over the counter; PPIs, proton pump inhibitors; NSAIDs, nonsteroidal anti-inflammatory drugs; $\mathrm{H} 2$, histamine 2 .

antibiotics (10\%). Of the respondents, $56(48 \%)$ reported folic acid and/or vitamin D use during pregnancy. Information about medication was obtained by 76 women (67\%). Most used information sources were the Internet, PIL, and GP.

\section{Concerns}

Pregnant women were most concerned (score 4 or 5 on the concern score) about having a child with a congenital birth defect (35\%), having a miscarriage $(35 \%)$, or having a child with an increased risk of an allergic disease (23\%), respectively, as a result of their drug use. The different concerns pregnant women had regarding medication use during pregnancy are presented in Figure 1.

\section{Perceptions of risk and benefits}

Highest risk scores were reported for antidepressants, sedatives/anxiolytics, and NSAIDs, respectively. Highest benefit scores were reported for antibiotics, antifungal medication, and antacids. Mean risk and benefit scores, including Pearson correlation coefficients, are presented in Figure 2. Risks and benefit scores were significantly inversely correlated for most of the drug classes. Almost half of the drug classes were perceived as low in risk (mean score $<3.5$ ) and high in benefit (mean score $>3.5$ ). In addition, Figure 2 shows 


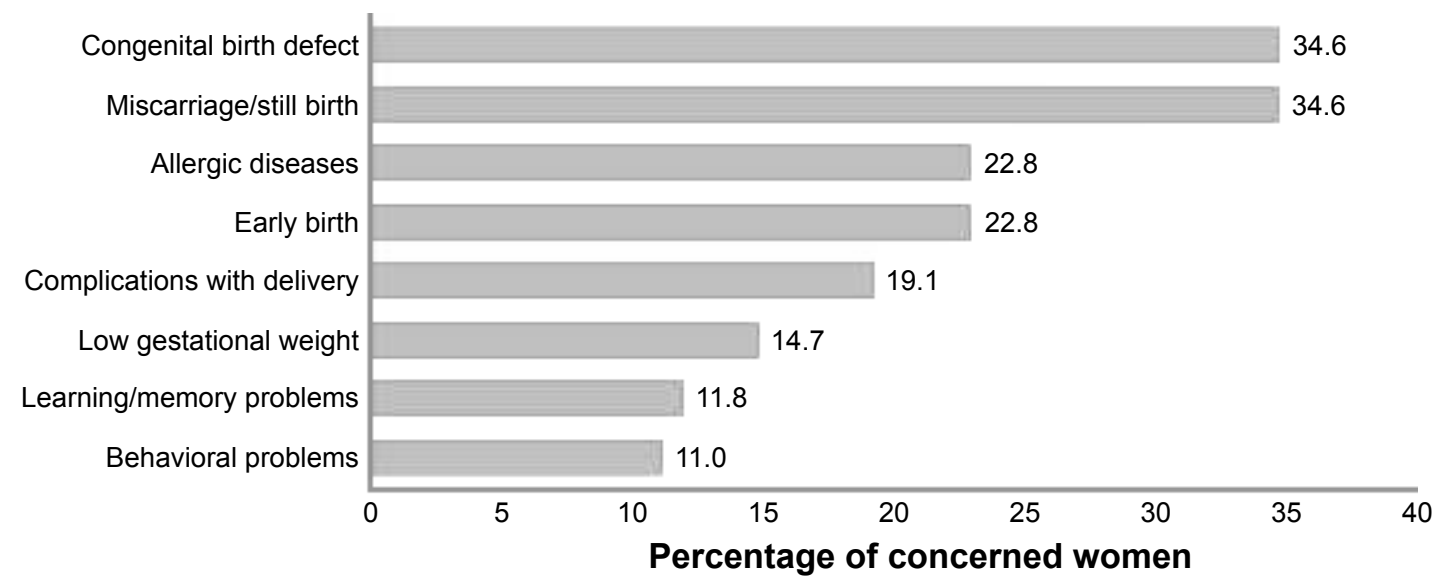

Figure I Percentage of women who were either often or always concerned about different outcomes due to medication use during pregnancy.

that the spread of mean values of the different drugs on the risk scale is higher (from 1.9 to 5.3) than the spread of mean values of the different drugs on the benefit scale (from 3.3 to 4.7).

Analysis of the weighted sum risk score showed that women in the first 2 trimesters of pregnancy perceived significantly higher risks of medication use $(p=0.007)$. The remaining characteristics, namely, education, maternal age, employed in health care sector, nulliparity, previous miscarriages, smoking during pregnancy, and use of medication showed no statistically significant differences in weighted risk sum scores. Lower benefit scores of medication use were perceived if women were single $(p=0.014)$, smoking during

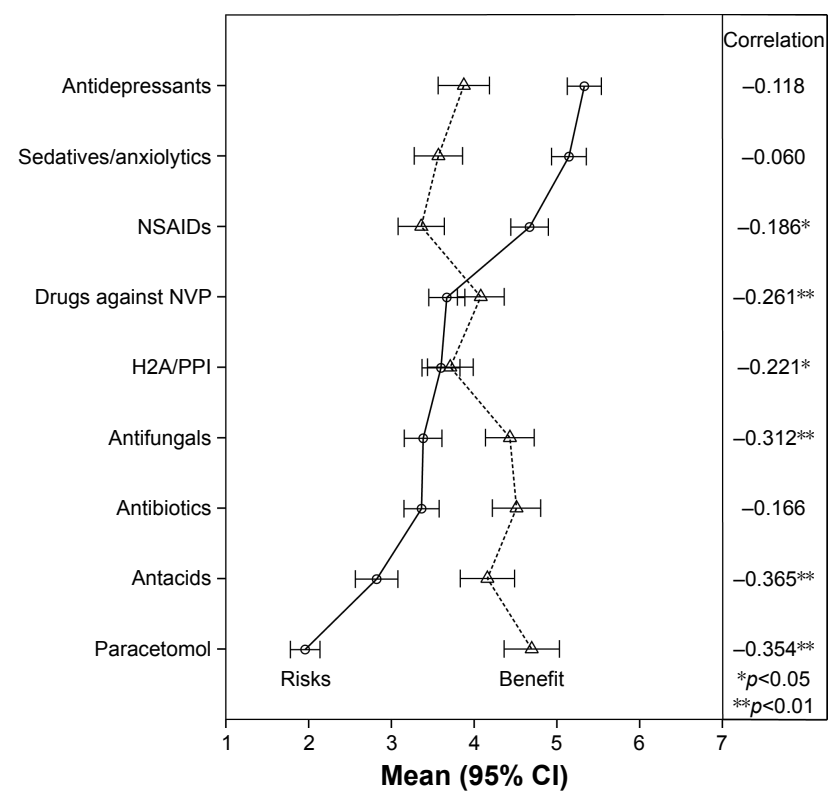

Figure 2 Means of the perceived risk and perceived benefits of different medication groups during pregnancy.

Abbreviations: NVP, nausea and vomiting during pregnancy; H2A/PPI, histamine-2 antagonist/proton pump inhibitor; NSAIDs, nonsteroidal anti-inflammatory drugs. pregnancy $(p=0.028)$, nulliparous $(p=0.006)$, or did not have a family history of birth defects $(p=0.005)$.

\section{Discussion}

\section{Main findings}

Women were most concerned that medication use during pregnancy could result in a child with a congenital birth defect, a miscarriage, or a child with an allergic disease. Most of the drug classes were perceived relatively low in risk and high in benefit. Only antidepressants, sedatives/anxiolytics, and NSAIDs were perceived as high-risk medication. Women had higher risk perception scores during early trimesters of pregnancy. Lower benefit scores were perceived if women were single, nulliparous, smoking during pregnancy, or had no family history of birth defects.

\section{Strengths and limitations}

Our study is the first to investigate the perceived risk-benefit balance with regard to medication use during pregnancy. Another major strength of our study is the method of inclusion. In previous risk perception studies, women were invited to participate in the studies when visiting websites containing pregnancy-related information. ${ }^{12,15}$ In our opinion, this could have led to a selection bias and the inclusion of more concerned women. Since women were included independent of their information seeking behavior in the current study, the influence of this type of selection bias will likely be less. The women included in the study were representative of the general Dutch population of pregnant women with respect to age (age of the general pregnant population was 31 years vs 31 years in this study population) and education level (high education of $40 \%$ in the general population vs $42 \%$ in the study population). ${ }^{30,31}$ Further, all participants were 
asked to fill out the questionnaire while they were pregnant. With this approach, the outcome of the pregnancy could not have influenced their risk perceptions. It should, however, be noted that most women completed the questionnaire while they were in their third trimester. In the third trimester, the likelihood of an abortion is low and congenital anomalies already may have been detected via ultrasound. In addition, recall bias regarding medication use will be minimal when asked during pregnancy. ${ }^{32}$ Another strength of our study is the questionnaire design, because information about medication use was obtained with both open and closed questions. It has been reported that prevalence estimates are higher when questions include indications or specific drugs when compared to open-ended questions. ${ }^{33}$ The use of the weighted risk and benefit sum scores was another advantage of this study. The weighted sum scores represent unbiased estimates of standardized values on a latent variable (eg, "overall perceived benefit").

Apart from these strengths, potential limitations need to be discussed. First, we included all pregnant women who were attending first and second-line care facilities, regardless of their health status or antenatal care, to reduce the risk of sampling bias. Although every pregnant woman living in the Netherlands can undergo a prenatal screening, the majority of our study population consisted of women who came for a routine follow-up with an obstetrician. We could, therefore, not exclude the possibility that the study population differed from the general birthing population. Nevertheless, as stated above, the distribution of age and level of education was similar between the study population and the general birthing population in the Netherlands. ${ }^{30,31}$

Second, all women understood the Dutch language; however, the extent to which they understood the questions that were asked was not assessed.

Third, though the response rate was rather high for a questionnaire study (77\%) and associations were significant in most evaluations, the total number of participants was low. Due to the low statistical power, we could not perform comparisons between women who were prescribed specific drugs and women who were not. Such analyses would show how actual users balance the risks and benefits of a specific drug and would represent the potential noncompliance in that population.

Fourth, we compared risks and benefits for drug classes instead of specific drugs within the drug classes. In relation to the measurement of concerns, questions were asked about concerns for "any medication" rather than concerns related to a specific medication. This made our questions more comprehensible by pregnant women; however, since there may be variation within and between each drug class, findings cannot be interpreted for specific drugs. We did not provide the option of "do not know" when asked for the perception of risks and benefits. The number of unfilled responses regarding risks and benefits was low and ranged from 4 (paracetamol) to 9 (drugs against NVP) for questions about risks and ranged from 3 (paracetamol) to 6 (antibiotics) for the questions about benefits. It is also possible that participants listed the mid-value if they did not know the medication group described. It is unclear to what extent this influenced the results.

Fifth, interpretations were given only for scores 1 and 7 of the 7-point Likert scales. It is not correct to infer that the intensity of feeling between 1 and 7 is equivalent to the intensity of feeling between other consecutive categories on the Likert scale. It could not be excluded that the differences in the perception of risks and benefits were due to interpersonal differences in interpretation of the values of the scale.

Sixth, the reliability and validity of the questionnaire were not assessed and it is unclear how this could have affected the results of this study.

\section{Interpretation and comparison with literature}

Women were most concerned that medication use during pregnancy could result in a child with a birth defect, a miscarriage, or a child who develops an allergic disease. Although different studies have investigated the different worries of pregnant women in general, ${ }^{21}$ this is the first study that reports women's concerns regarding medication use during pregnancy.

Different studies reported that risks associated with medication use were perceived higher than actual risks. ${ }^{2-15}$ However, it has been considered that the relativeness of risk perceptions is more interesting than the mean risk perceptions itself. ${ }^{12}$ From the different drug classes, sedatives and antidepressants were perceived highest in risk and paracetamol and antacids were perceived lowest. This is in accordance with findings from a recent study in Norway. ${ }^{12}$ In the current study, women were not asked to rate the absolute risks of the different drug classes and the results of this study cannot be compared with true risks. However, for the drug classes perceived highest in risk, teratogenicity has been described in the literature and the product information of several products from these classes.

Recent studies have shown that pregnant women overestimate the teratogenic risk of medication use. ${ }^{2-15}$ However, this study showed that women perceive benefits of medication use as well. When risks were balanced with benefits, 
most of the drugs were perceived relatively low in risk and high in benefit. Risks and benefits were significantly negatively correlated for most of the drugs. This confounding of risks and benefits in women's minds may implicate that it is possible to change the risk perception by changing the perception of benefits of medication use..$^{33}$ The variance of perceived risks was higher than the variance of perceived benefits between the different drug classes (Figure 2). That risk scores were rated with more extreme values than the benefit scores may indicate that women have more difficulty rating the benefits of medication use than the risks. Including more information about the benefits of medication use during counseling may play an important role in lowering risk perceptions among pregnant women. ${ }^{34}$

Analyses of the weighted risk sum score showed that women perceived higher risks during the first 2 trimesters of pregnancy than women in the third trimester of pregnancy. In the first trimester, organogenesis takes place and risks on spontaneous abortion and congenital anomalies are highest. However, recently it has been stated that exposures during the third trimester can also have negative implications for the child for certain pediatric outcomes. ${ }^{16,17}$

Analyses of the weighted benefit sum score showed that women perceived lower benefit scores if they were single, smoking, or nulliparous. Since no earlier research focused on the potential benefits of medication use during pregnancy, we can only speculate about potential explanations. Single women lack the option to discuss their concerns and fears with a partner, which may contribute to a more cautious attitude toward medication use during pregnancy and lower perceived benefit scores. Nulliparous women may also have a more cautious attitude toward medication use during pregnancy, since they had never experienced a pregnancy before. In addition, a previous study performed in Norway found that nulliparous women perceived higher risks of medication use during pregnancy. ${ }^{12}$ Women who smoked during pregnancy more often tend to have a low socioeconomic status. In addition, the vision of these women on a healthy pregnancy may be different, since they maintain an unhealthy lifestyle even when they are pregnant. They may therefore not fully comprehend the potential benefits of medication use during pregnancy. Moreover, none of the women indicated having consumed alcohol during pregnancy, which is unlikely. The influence of response bias cannot be ruled out and it is unclear how this could affect the results.

Women with a family history of birth defects perceived higher benefit scores of medication use during pregnancy. These women may have more knowledge about medication use during pregnancy, especially about the benefits. For example, they may be aware that folic acid supplementation may prevent certain birth defects.

\section{Conclusion}

This study shows that concerns regarding medication use during pregnancy are not restricted to having a child with a congenital birth defect only. Although pregnant women overestimate the teratogenic risk of medication use, most of the drugs were perceived relatively low in risk and high in benefit. Health care providers can take this into account when counseling pregnant women.

\section{Acknowledgments}

The authors wish to thank the Department of Obstetrics and Gynaecology of the Medical Centre Leeuwarden and the prenatal screening facility SICHT who contributed in the inclusion of pregnant women.

This study was financed by the Department of Pharmacy, University of Groningen. The funder had no role in the study design; collection, analysis, and interpretation of data; writing of the report; or the decision to submit the paper for publication. The corresponding author had full access to all data and the final responsibility for the decision to submit the study for publication.

This research was presented as an oral presentation at the International Congress of Behavioral Medicine from August 20, 2014 to August 23, 2014 in Groningen, the Netherlands and as a poster at the International Conference on Pharmacoepidemiology and Therapeutic Risk Management from October 24, 2014 to October 27, 2014 in Taipei, Taiwan.

\section{Disclosure}

All authors declare that they had support from the Department of Pharmacy, University of Groningen, for the submitted work; had no financial relationships with any organization that might have an interest in the submitted work in the previous 3 years; had no other relationships or activities that could appear to have influenced the submitted work; and report no conflicts of interest in this work.

\section{References}

1. Bakker MK, Jentink J, Vroom F, Van Den Berg PB, De Walle HE, De Jong-Van Den Berg LT. Drug prescription patterns before, during and after pregnancy for chronic, occasional and pregnancy-related drugs in the Netherlands. BJOG. 2006;113:559-568.

2. Widnes SF, Schjott J, Eide GE, Granas AG. Teratogenic risk perception and confidence in use of medicines in pairs of pregnant women and general practitioners based on patient information leaflets. Drug Saf. 2013;36:481-489.

3. Csajka C, Jaquet A, Winterfeld U, Meyer Y, Einarson A, Panchaud A. Risk perception by healthcare professionals related to drug use during pregnancy: a Swiss survey. Swiss Med Wkly. 2014;7(144):w13936. 
4. Koren G, Bologa M, Long D, Feldman Y, Shear NH. Perception of teratogenic risk by pregnant women exposed to drugs and chemicals during the first trimester. Am J Obstet Gynecol. 1989;160(5 Pt 1): $1190-1194$.

5. Koren G, Pastuszak A. Prevention of unnecessary pregnancy terminations by counselling women on drug, chemical, and radiation exposure during the first trimester. Teratology. 1990;41(6):657-661.

6. Mazzotta P, Magee LA, Maltepe C, Lifshitz A, Navioz Y, Koren G. The perception of teratogenic risk by women with nausea and vomiting of pregnancy. Reprod Toxicol. 1999;13(4):313-319.

7. Pole M, Einarson A, Pairaudeau N, Einarson T, Koren G. Drug labeling and risk perceptions of teratogenicity: a survey of pregnant Canadian women and their health professionals. J Clin Pharmacol. 2000;40(6): 573-577.

8. Jasper JD, Goel R, Einarson A, Gallo M, Koren G. Effects of framing on teratogenic risk perception in pregnant women. Lancet. 2001; 358(9289):1237-1238.

9. Sanz E, Gomez-Lopez T, Martinez-Quintas MJ. Perception of teratogenic risk of common medicines. Eur J Obstet Gynecol Reprod Biol. 2001; 95(1):127-131.

10. Koren G, Levichek Z. The teratogenicity of drugs for nausea and vomiting of pregnancy: perceived versus true risk. Am J Obstet Gynecol. 2002;186(5 Suppl Understanding):S248-S252.

11. Bonari L, Koren G, Einarson TR, Jasper JD, Taddio A, Einarson A. Use of antidepressants by pregnant women: evaluation of perception of risk, efficacy of evidence based counseling and determinants of decision making. Arch Womens Ment Health. 2005;8(4):214-220.

12. Nordeng H, Ystrom E, Einarson A. Perception of risk regarding the use of medications and other exposures during pregnancy. Eur J Clin Pharmacol. 2010;66(2):207.

13. Behringer T, Rollman BL, Herbeck-Belnap B, Houck PR, Mazumdar S, Schwarz EB. Impact of physician counseling and perception of teratogenic risks: a survey of 96 nonpregnant women with anxiety. Prim Care Companion CNS Disord. 2011;13(2):pii:PCC.10m01028.

14. Walfisch A, Sermer C, Matok I, Einarson A, Koren G. Perception of teratogenic risk and the rated likelihood of pregnancy termination: association with maternal depression. Can J Psychiatry. 2011;56(12): 761-767.

15. Petersen I, McCrea RL, Lupattelli A, et al. Women's perception of risks of adverse fetal pregnancy outcomes: a large-scale multinational survey. BMJ Open. 2015;5:e07390.

16. Briggs GG, Freeman RK, Yaffe SJ. Drugs in pregnancy and lactation: a reference guide to fetal and neonatal risk. Philadelphia: Lippincott Williams \& Wilkins; 2012.

17. Mulder B, Schuiling-Veninga CC, Bos JH, de Vries TW, Hak E. Acid-suppressive drug use in pregnancy and the toddler's asthma risk: a crossover, case-control study. J Allergy Clin Immunol. 2013;132(6): $1438-1440$.

18. Toh S, Mitchell AA, Louik C, Werler MM, Chambers CD, HernándezDíaz S. Antidepressant use during pregnancy and the risk of preterm delivery and fetal growth restriction. J Clin Psychopharmacol. 2009; 29(6):555-560.
19. Schirm E, Meijer WM, Tobi H, De Jong-van den Berg LTW. Drug use by pregnant women and comparable non-pregnant women in the Netherlands with reference to the Australian classification system. Eur J Obstet Gynecol Reprod Biol. 2004;114:182-188.

20. WINap Geneesmiddel Informatie en Wetenschapswinkel Groningen: Zelfzorgmedicijnen tijdens zwangerschap en borstvoeding; wat kan ik doen, wat mag ik slikken? Groningen; 2004.

21. Petersen JJ, Paulitsch MA, Guethlin C, Gensichen J, Jahn A. A survey on worries of pregnant women - testing the German version of the Cambridge Worry Scale. BMC Public Health. 2009;9:490.

22. Austin JC. Re-conceptualizing risk in genetic counseling: implications for clinical practice. J Genet Counsel. 2010;19:228-234.

23. Brewer NT, Chapman GB, Gibbons FX, Gerrard M, McCaul KD, Weinstein ND. Meta-analysis of the relationship between risk perception and health behavior: the example of vaccination. Health Psychology. 2007;26:136-145.

24. Weinstein ND, Kwitel A, McCaul KD, Magnan RE, Gerrard M, Gibbons FX. Risk perceptions: assessment and relationship to influenza vaccination. Health Psychology. 2007;26;146-151.

25. Zwart O, Veldhuijzen IK, Elam G, et al. Perceived threat, risk perception and efficacy beliefs related to SARS and other (emerging) infectious diseases: Results of an International survey. Int J Behav Med. 2009: 16:30-40.

26. Slovic P, Peters E, Grana J, Berger S, Dieck GS. Risk perception of prescription drugs: results of a national survey. Drug Inform J. 2007;41(1): $81-100$.

27. Beyer AR, Fasolo B, Phillips LD, de Graeff PA, Hillege HL. Risk perception of prescription drugs: results of a survey among experts in the European regulatory network. Med Decis Making. 2013;33(4): 579-592.

28. Heaman MI, Gupton AL. Psychometric testing of the perception of pregnancy risk questionnaire. Res Nurs Health. 2009;32(5):493-503.

29. Carroll SJ, Paquet C, Howard NJ, Adams RJ, Taylor AW, Daniel M. Validation of continuous clinical indices of cardiometabolic risk in a cohort of Australian adults. BMC Cardiovasc Disord. 2014;14:27.

30. CBS (Centraal Bureau voor de Statistiek). Available from: http:// statline.cbs.n1/StatWeb/publication/?DM=SLNL\&PA=37422ned\&D $1=0,4-5,19,21,23-24,26,35,40,42,47 \& \mathrm{D} 2=0,10,20,30,40,50,60,(1-1)-$ $1 \& \mathrm{VW}=\mathrm{T}$. Accessed October 4, 2013

31. CBS. Bevolkingsprognose 2012-2060: veronderstellingen over de geboorte. Available from: http://www.cbs.n1/NR/rdonlyres/3BA03CC0F684-4481-946E-BB4338AF1083/0/20131002b15art.pdf. Accessed October 4, 2013.

32. van Gelder MM, van Rooij IA, de Walle HE, Roeleveld N, Bakker MK. Maternal recall of prescription medication use during pregnancy using a paper-based questionnaire. Drug Saf. 2013;36(1):43-54.

33. Klungel OH, de Boer A, Paes AH, Herings RM, Seidell JC, Bakker A. Influence of question structure on the recall of self-reported drug use. J Clin Epidemiol. 2000;53(3):273-277.

34. Alhakami AS, Slovic P. A psychological study of the inverse relationship between perceived risk and perceived benefit. Risk Anal. 1994; 14(6):1085-1096
Patient Preference and Adherence

\section{Publish your work in this journal}

Patient Preference and Adherence is an international, peer-reviewed, open access journal that focuses on the growing importance of patient preference and adherence throughout the therapeutic continuum. Patient satisfaction, acceptability, quality of life, compliance, persistence and their role in developing new therapeutic modalities and compounds to optimize

\section{Dovepress}

clinical outcomes for existing disease states are major areas of interest for the journal. This journal has been accepted for indexing on PubMed Central. The manuscript management system is completely online and includes a very quick and fair peer-review system, which is all easy to use. Visit http://www dovepress.com/testimonials.php to read real quotes from published authors. 